Theories \& Applications, the International Edition

Printed Version: (ISSN 2090-5262)

Online Version: (ISSN 2090-5270)

March 2013, Volume 3, No. 1 Pages (7 - 13)

\title{
The Effect of Hathayoga on the Immune System and mood state, in Female Breast Cancer Patients After Mastectomy
}

\author{
Sheren M Abdelhamed*, Saad Elosh**, Waleed Hammouda*** \\ *Faculty of Physical Education,Training and Gymnastic Department Monofia university \\ **Prof. of clinical pathology \\ ***Prof. of oncology, Zagazig university
}

\begin{abstract}
Distress in breast cancer patients can cause complications and delay recovery from surgery. The aim of our study was to evaluate the effects of yoga intervention on postoperative outcomes in operable breast cancer patients; In Zagaaig university hospitals this study included (Twenty eight) female patients diagnosed stage I, II and stagel11 breast cancer patients were recruited in a randomized controlled trial comparing the effects of a yoga program (Hatha type) group A (14 patients) versus other control group (14 patients ). Subjects were assessed for, assessment of selfreported anxiety, depression, and immunity in form of (T lymphocyte subsets (CD4\%,CD8 \% and natural killer (NK) cell counts) and serum immunoglobulins (IgG, IgA and IgM). The results suggest a significant improvement in the psychosocial outcomes and immunity in the yoga group ( $P$ $<0.001)$, as compared to the controls We conclude that: The results suggest possible benefits of yoga in reducing postoperative complications and improvement of the life quality.
\end{abstract}

Keywords: Cancer, immunity, surgery, yoga.

\section{Introduction}

$\mathrm{H}$ athayoga considered the best type of Hathayoga mean balance and it a combination between Asana which movemements and body postures and Pranayama It consists of a series of breathing exercises(regulated nostril breathing) also Yoga is one such psychotherapeutic intervention that has been used in numerous health care concerns where stress was believed to play a role. hathayoga is considered the connection between brain and body (1) HathaYoga is the best type of yoga and sports as it is played with a slow motion that can be graduated also it improve the respiratory ,cardiac ,and deglutition systems also it improve the muscular strength and range of movements especially after a surgery like breast surgery (2) also in a review by Ahmed (3) he pointed to the effect of stress and depression on the stress hormonal secretions by the endocrine system which lead to appearance of the undesired symptoms of anxiety. Some studies which were published in the proceeding of the national academy of science an journal of American academy of dermatolog, the immune system in human can be affected directly to the daily stress and depression also the melanin bodies in the skin also its production rapidly affected by the stress and quality of lif( 4 ) Yoga, an ancient Eastern spiritual discipline, is one of the most widely used mind-body therapies among Americans today, Yoga is based in the practice of physical postures, breathing techniques, and meditation. Philosophically, yoga is aimed towards increasing mastery of the body and breath to achieve mastery of the mind, with the ultimate goal of developing deeper spiritual awareness and connection ( 5 ) on the other side some authors (6) published that the psychological state and the depression affected negatively on the acceptance of chemotherapy and radiotherapy after breast surgery and vice versa on the improvement of patients health via increase of B cells and NK cells. Several metaanalyses of presurgical intervention studies have argued that association between presurgical 
intervention and clinical outcome is clinically meaningful. . A growing body of randomized controlled research on yoga suggests that yoga may exert physical and psychological benefits in both healthy and chronically ill individuals. ( 7 ) There are no known studies of yoga among ethnic minority or underserved cancer patients. the unique spiritual and meditative dimensions, its applicability to the cancer patients is the focus of this study. Specifically, this study examines the impact of yoga on overall immunity, fatigue, psychological distress, and spiritual well-being among a sample of breast cancer patients

\section{Patients and methods}

The study: was a randomized controlled trial conducted in the oncology unit of Zagazig University Hospital, for female patients with early breast cancer stage 1, 11 and 111 . The patients number was $(n=28)$ that were grouped into 2 groups 14 people each .Group A ( $n=14$ yoga) was subjected to Hathayoga and group $B(n=14$ control) was the control group.

The procedure: We started the procedure two weeks after mastectomy after removal of the stitches and wound healing was completed, through the period of chemotherapy.

\section{Inclusion criteria:}

All patients after mastectomy stage 1,11and 111.

Age: 30 to 45 years old

Weight: 65 to $80 \mathrm{~kg} /$ height: 155 to $170 \mathrm{~cm}$.

Exclusion criteria Patients with history of (chronic heart or lung disease / liver or renal cell failure / rheumatic and rheumatoid disease / Alzheimer / schizophrenia / immune system disorder / chronic psychological disorder) (table 1)

\section{Program of Hathayoga}

The program consists of group of fixed body positions and breathing exercise with deep mental and physical relaxation to achieve psychological calmness

The program is designed in sessions 20 to 45 min. each 3 times / week, for 12 weeks

Intensity 50 - 60\%, pulse was used as an indicator for it
Pulse =percent of training $\%$ ( highest pulse resting pulse) +resting pulse

Highest pulse $=220-$ age, resting pulse $(70$ per minute)

The gradual increase in intensity through increasing the speed of exercise period of posture stability. Demographic information, clinical data, and investigative notes were taken during their initial visit before the program. About $12 \mathrm{ml}$ of blood sample was collected in vacuettes under sterile conditions on the day of the surgery. Blood samples were collected between 7 a.m. to 11 a.m. for all participants to reduce diurnal variability to evaluate the plasma cells and tymphocytes (immunoglobulins IgG ,IgM and IgA ) CD4.CD8,CD56 and Killer cells (IK cells ) Differences in the preoperative nutritional status of the subjects could have confounded the observations in this study.

\section{Results}

serum samples were assessed for Immunoglobulins $\mathrm{G}, \mathrm{M}$ and $\mathrm{A}$ at baseline following before and after intervention. A paired samples $\mathrm{t}$ test showed a significant increase in IgA levels following surgery in the control group but no significant changes in the yoga group. Analysis of covariance using the

baseline pretest measure as a covariate also showed a significant decrease in $\operatorname{Ig} \mathrm{A}$ levels in the yoga group [as compared to the controls. There was no significant within- and between group changes in $\mathrm{IgM}$ and $\mathrm{IgG}$ levels.

T Lymphocyte subsets such as CD4+, CD8+ and CD56+\% were assessed before and after four weeks after test. A paired samples t test done to assess the changes in CD56\% following surgery within groups showed a significant decrease in CD56 \% following surgery in the control group but not in the yoga group. Analysis of variance done on these postmeasures using the baseline measure of CD56 $\%$ as a covariate showed significantly higher levels of CD56 \% in the yoga group as compared to the controls. A paired samples, $\mathrm{t}$ test done to assess the changes in CD4\% and CD8 \% following surgery within groups showed a significant decrease in both CD4\% and $\mathrm{CD} 8 \%$ counts in the control group but not in the yoga group. 
Table 1

demonstrates the demographic data of the patients including the Age, weight and breast cancer stages with significant differences in both groups

\begin{tabular}{|l|l|l|l|}
\hline Patients cherecters & Group A & Group B & P v \\
\hline Age (range ) & $(30-41) 39 \pm 3.1$ & $(30-41) 40 \pm 2.1$ & 1.691 \\
\hline Weight & $(155-182) 170 \pm 2.1$ & $(160-170) 160 \pm 1.2$ & 0.240 \\
\hline Height & $(60-82) 70 \pm 3.1$ & $(77-90) 79 \pm 2.6$ & 1.315 \\
\hline Stages of the disease & & & ns \\
Stage 1 & 6 & 5 & \\
Stage 11 & 3 & 5 & \\
Stage 111 & 5 & 4 & \\
\hline & & & \\
\hline
\end{tabular}

Table 2

The immunity measures and mood state before test intervention in both groups ,the control and Yoga groups $(\mathrm{N}=14)$

\begin{tabular}{|c|c|c|c|c|c|c|}
\hline \multirow[t]{2}{*}{ variables } & \multicolumn{2}{|c|}{ Control Group } & \multicolumn{2}{|c|}{ Yoga group } & \multirow{2}{*}{$\begin{array}{l}\text { Diff .in } \\
. M\end{array}$} & \multirow[t]{2}{*}{ T. v } \\
\hline & $\mathrm{M}$ & $\mathrm{SD}$ & $\mathrm{M}$ & SD & & \\
\hline $\mathrm{IgG}$ & 1.207 & 0.107 & 1.136 & 0.108 & 0.071 & 1.691 \\
\hline$\overline{I g M}$ & 0.800 & 0.088 & 0.807 & .0062 & 0.007 & 0.240 \\
\hline $\operatorname{IgA}$ & 5.643 & 0.372 & 5.443 & .403 & 0.200 & 1.315 \\
\hline CD4 & 38.357 & 2.499 & 38.857 & 2.931 & 0.500 & 0.468 \\
\hline CD8 & 36.286 & 2.920 & 35.500 & 2.565 & 0.786 & 0.729 \\
\hline CD56 & 20.786 & 1.424 & 20.143 & 1.231 & 0.643 & 1.231 \\
\hline N.K.(T) & 0.434 & 0.102 & 0.435 & 0.106 & 0.001 & 0.035 \\
\hline Mood state & 34.143 & 3.592 & 35.214 & 3.167 & 1.071 & 0.807 \\
\hline
\end{tabular}

There were no significant difference regarding the immunity measures and mood state before test intervention in both groups the control and Yoga groups 
Table 3

Yoga group $(\mathrm{N}=14)$

\begin{tabular}{|c|c|c|c|c|c|c|c|c|}
\hline \multirow[t]{2}{*}{ Variables } & \multicolumn{2}{|l|}{ Before } & \multicolumn{2}{|l|}{ After } & \multirow{2}{*}{$\begin{array}{l}\text { Diff/.in } \\
M\end{array}$} & \multirow[t]{2}{*}{ S.M ${ }^{2}$} & \multirow[t]{2}{*}{ T value } & \multirow{2}{*}{$\begin{array}{l}\text { Improve } \\
\text { ment }\end{array}$} \\
\hline & $\mathrm{M}$ & $\mathrm{SD} \pm$ & $\mathrm{M}$ & $\mathrm{SD} \pm$ & & & & \\
\hline $\mathrm{IgG}$ & 1.136 & 0.108 & 1.600 & 0.068 & 0.036 & 0.132 & 1.325 & 3.14 \\
\hline $\operatorname{IgM}$ & 0.807 & 0.062 & 0.714 & 0.053 & 0.007 & 0.009 & 1.000 & 0.88 \\
\hline $\operatorname{IgA}$ & 5.643 & 0.372 & 5.421 & 0.519 & 0.221 & 2.844 & 1.771 & 3.92 \\
\hline CD4 & 38.857 & 2.931 & 36.643 & 5.813 & 2.214 & 272.457 & 1.810 & 5.70 \\
\hline CD8 & 35.500 & 2.565 & 32.571 & 7.079 & 2.929 & 382.929 & 2.019 & 8.25 \\
\hline CD56 & 20.143 & 1.23 & 22.429 & 1.785 & 2.286 & 44.857 & 4.604 & 11.35 \\
\hline N.K.(T) & 0.435 & 0.106 & 0.458 & 0.106 & 0.023 & 0.024 & 1.987 & 5.25 \\
\hline $\begin{array}{l}\text { Mood } \\
\text { state }\end{array}$ & 35.214 & 3.167 & 19.071 & 1.207 & 16.143 & 107.714 & 20.984 & 45.84 \\
\hline
\end{tabular}

$\mathrm{T}=2.0160$ (means and $\mathrm{SD} \pm$ variables)

There were a significant difference regarding to the immunity measures and mood state before and after test intervention in Yoga groups with post test improvement,

Table 4

Control group; $\mathrm{N}=14$ means and $\mathrm{SD} \pm$ variables

The immunity measures and mood state before and after test intervention in

\begin{tabular}{|c|c|c|c|c|c|c|c|c|}
\hline \multirow[t]{2}{*}{ Variables } & \multicolumn{2}{|l|}{ After } & \multicolumn{2}{|l|}{ Before } & \multirow{2}{*}{$\begin{array}{l}\text { Diff./in } \\
. \mathrm{M}\end{array}$} & \multirow[t]{2}{*}{$\overline{S . M^{2}}$} & \multirow[t]{2}{*}{$\mathrm{T}$ value } & \multirow{2}{*}{$\begin{array}{l}\text { Improve } \\
\text { ment }\end{array}$} \\
\hline & $\mathrm{M}$ & $\mathrm{SD} \pm$ & $\mathrm{M}$ & $\mathrm{SD} \pm$ & & & & \\
\hline $\mathrm{IgG}$ & 1.364 & 0.388 & 1.207 & 0.107 & 0.157 & 1.914 & 1.532 & 13.02 \\
\hline IgM & 0.921 & 0.070 & 0.800 & 0.088 & 0.021 & 0.044 & 1.385 & 2.68 \\
\hline $\operatorname{IgA}$ & 7.229 & 0.375 & 5.443 & 0.403 & 1.786 & 5.177 & 10.588 & 32.81 \\
\hline CD4 & 37.357 & 1.865 & 38.357 & 2.499 & 1.000 & 78.000 & 1.528 & 2.61 \\
\hline CD8 & 34.857 & 1.916 & 36.286 & 2.920 & 1.429 & $\begin{array}{l}117.42 \\
9\end{array}$ & 1.778 & 3.94 \\
\hline CD56 & 17.571 & 1.158 & 20.786 & 1.424 & 3.214 & 38.357 & 7.002 & 15.46 \\
\hline N.K.(T) & 0.346 & 0.057 & 0.434 & 0.102 & 0.088 & 0.049 & 5.363 & 20.26 \\
\hline Mood state & 29.286 & 1.773 & 34.143 & & 4.857 & $\begin{array}{l}113.71 \\
4\end{array}$ & 6.145 & 14.23 \\
\hline
\end{tabular}

$$
\mathrm{T}=2.1607
$$

There were a significant difference regarding to the immunity measures and mood state before and after test intervention in control group 
Table 5

Yoga and control groups $(\mathrm{N}=28)$

\begin{tabular}{|l|l|l|l|l|l|l|}
\hline \multirow{2}{*}{ Variables } & \multicolumn{2}{|l|}{ Control Group } & \multicolumn{2}{l|}{ Yoga group } & \multicolumn{2}{l|}{$\begin{array}{l}\text { Diff. In } \\
\text { M T test }\end{array}$} \\
\cline { 2 - 6 } & M & SD & M & SD & & \\
\hline IgG & 1.364 & 0.388 & 1.600 & 0.068 & 0.264 & 2.422 \\
\hline IgM & 0.921 & 0.070 & 0.714 & 0.053 & 0.007 & 0.293 \\
\hline IgA & 7.229 & 3.75 & 5.421 & 0.519 & 1.807 & 10.174 \\
\hline CD4 & 37.357 & 1.865 & 36.643 & 5.813 & 0.714 & 0.422 \\
\hline CD8 & 34.857 & 1.916 & 32.571 & 7.079 & 2.286 & 1.124 \\
\hline CD56 & 17.571 & 1.158 & 22.429 & 1.785 & 4.857 & 8.230 \\
\hline N.K.(T) & 0.346 & 0.057 & 0.458 & 1.106 & 0.112 & 3.362 \\
\hline Mood state & 29.286 & 1.77 & 190.71 & 1.207 & 10.214 & 17.173 \\
\hline
\end{tabular}

$\mathrm{T}=2, .056$ (means and $\mathrm{SD} \pm$ variables) There were a statistical significant difference regarding to the immunity measures and mood state after test intervention in Control and Yoga groups; in favor of the Yoga group

\section{Discussions:}

Analysis of our results in table 1.2 ,we had a statistical significant difference between the two groups in pre and post measures regarding to the stress behaviors and depression in favor of group A (Yoga group). Our findings are consistent with earlier studies using behavioral and relaxation approaches to improve postoperative outcomes, and agree the results published by Linda E et al 2003 (8) as he stated that the Yoga program had an important role in decreasing the depression and stress in patients postoperative and improve life quality in old peoples. Agree other study in 2004 by Woolery et al (9)they stated that yoga intervention had a suppressive effect on the stress symptoms and anxiety

In terms of the immune results, $\operatorname{IgG}, \operatorname{IgM}, \operatorname{IgA}$ in table 2,3 There was no significant changes within- and between groups changes in IgM and IgG levels versus increase in the IgA level in the control group. Although studies have shown various stress reduction interventions to modulate serum IgA levels and lymphocyte the fact that yoga helped decrease IgA levels among the Yoga group. This is because earlier studies( Ahmed et al ) (10) have shown that the tumor load is directly related to the serum IgA levels in breast cancer patients. On the contrary, it can also be argued that yoga also helped reduce stress and improved anti-tumor immune responses that could have facilitated this change.

T Lymphocyte subsets such as CD4+, CD8+ and $\mathrm{CD} 56+\%$ were assessed before and after in Tables 2.4. A paired samples $\mathrm{t}$ test done to assess the changes in CD56 \% showed a significant changes before and after in the Yoga group and between the groups in favor of the Yoga group

Our intervention was helpful in reducing postoperative distress and anxiety and also helped improve immune responses in terms of changes in lymphocyte subpopulations indicating that it helped promote adaptation to this stressor.

The changes in lymphocyte subpopulations seen with yoga interventions could be attributed to stress reduction effects and adaptation to the stress of surgery that could have facilitated a decrease in distress and consequent improvement in immune outcomes. We had also no significant changes before and after after in CD4,CD8, \% in the control and Yoga groups Other study showed no changes in numbers of any of the lymphocyte subtypes overall lymphocyte numbers, were seen. Fawzy et al. (11)

Yoga effects on the immune system were not seen until 6 months after Yoga program. This also agree the study done by Raghavendra (12) 
et al where their results suggest a significant decrease in the state and trait of anxiety, depression symptom severity distress and improvement in quality of life in the yoga group as compared to the controls. There was also a significantly lesser decrease in $\mathrm{CD} 56 \%(\mathrm{P}=$ $0.02)$ and lower levels of serum $\operatorname{IgA}(\mathrm{P}=0.001)$ in the yoga group as compared to controls following surgery.

T Lymphocyte subsets such as CD4+, CD8+ and CD56+\% were assessed before and after in Tables 3,4 We showed increase in incidence of Nk cells ,tumor killer cells in Yoga group that agree with Studies by Dhabhar at al (13) they published that Catecholamines and glucocorticoids have been shown to rapidly and markedly affect the distribution of NK cells among different immune compartments and it may be hypothesized that changes in these hormone levels could be one of the mechanisms of action of our intervention

Also in other study by Ben-Eliyahu et a (14), in both animal models and humans have shown elevations in plasma levels of epinephrine and cortisol to reflect sympathetic nervous system activation and hypothalamopituitary axis activation. Coincidentally, such activation is also known to suppress NK cell activity, reduce lymphocyte proliferative responses to mitogens and bring about changes in lymphocyte subpopulations such as NK cell counts.

Such immune suppression following surgery in cancer patients has also been implicated in the promotion of metastasis via numerous mechanisms including the suppression of natural killer cell activity and counts by stress hormones

Another study by Whitehouse et al (15) showed that greater increases in relaxation in response to the intervention were associated with higher NK cell numbers and activity in healthy students taking medical exams. And agree the study done by lavey et al (16) on psychiatric patients it showed that greater increases in relaxation in response to the intervention were associated with higher NK cell numbers and activity

\section{Conclusion:}

Brest cancer in female patients had the risk of mood disturbance and depression, all these effects can be improved with Hath yoga training either before surgery or after in the period during chemotherapy and radiotherapy as in our study

\section{Reference:}

1)Mahmoud R,Yoga yhe method of happens ,health Cairo Egyptian ,Lebnae edi t1997

2) Harinath K, Malhotra AS, Pal K, Prasad R, Kumar R, Kain TC, et al . Effects of Hatha yoga and Omkar meditation on cardiorespiratory performance, psychologic profile and melatonin secretion. J Altern Complement Med 2004;10:261-8.

3)Ahmed O. The recent Psychology ;Cairo , Egyptian Langlo Lebrary ed. 2005

4. Wolsko PM, Eisenberg DM, Davis RB, et al: Use of mind-body medical therapies. J Gen Intern Med 2004; 19:43-50,

5. Rosenbaum E, Gautier H, Fobair P, et al: Cancer supportive care, improving the quality of life for cancer patients: A program evaluation report. Support Care Cancer 2004 ;12:293-301,

6. Khalsa SBS: Yoga as a therapeutic intervention: A biliometric analysis of published research studies. Indian J Physiol Pharmacol 2004;48:269-285,

7)Brown RP, Gerbarg PL. Sudarshan Kriya Yogic Breathing in the Treatment of Stress, Anxiety and Depression: Part II-Clinical Applications and Guidelines. J Altern Complement Med 2005;11:711-7.

8) linda e. carlson, phd, michael speca, psyd, kamala d. patel, phd, and eileen goodey, msw Mindfulness-Based Stress Reduction in Relation to Quality of Life, Mood,Symptoms of Stress, and Immune Parameters in Breast and Prostate CancerPsychosomatic Medicine 65:571-581 (2003)

9 )((Woolery A, Myers H, Sternlieb B, Zeltzerhg L.yoga intervention for young adults with elevated symptoms of depression)) . Altern Ther Health Med 2004;10:60-3.

10) Ahmed S, Faruqi NA, Arif SH, Akhtar S. Serum immunoglobulin levels in neoplastic disorder of breast. J Indian Med Assoc 2002;100:495-6. 
11) Fawzy FI, Kemeny ME, Fawzy NW, Elashoff R, Morton D, Cousins N, Fahey JL. A structured psychiatric intervention for cancer patients. II.Changes over time in immunological measures. Arch Gen Psychiatry 1990;47:729 35

12) Raghavendra $M$ Rao, Nagendra $H$ R, Nagarathna Raghuram, Vinay C, Chandrashekara S1, Gopinath K S2, Srinath B S2 Influence of yoga on mood states, distress, quality of life and immune outcomes in early stage breast cancer patients undergoing surgery Int J Yoga 06, 2009

13)Dhabhar FS, Miller AH, McEwen BS, Spencer RL. Effects of stress on immune cell distribution: Dynamics and hormonal mechanisms. J Immunol 1995;154:5511-27. 14)
Ben-Eliyahu S. Stress, Natural Killer cell activity and tumor metastasis: The role of catecholamines and corticosteroids. In: Levy E, Grauer D, Ben-Nathan, De-Kloet DR, editors. New frontiers in stress research: Modulation in brain function. Harwood Academic: Amsterdam; 1998 b. p. 203-15

15)Whitehouse WG, Dinges DF, Orne EC, Keller SE, Bates BL, Bauer NK,et al. Psychosocial and immune effects of selfhypnosis training for stress management throughout the fi rst semester of medical school. Psychosom Med 1996;58:249-63

16)Lavey R, Sherman T, Mueser KT, Osborne DD, Currier M, Wolfe R. The effects of yoga on mood in psychiatric in patients. Psychiatr Rehabil J 2005;28:399-402. 